\title{
Optimal Location of a Capacitor Bank in a Primary Feeder to Load up Linearly
}

\author{
Hermagasantos Zein ${ }^{1}$ and Erwin Dermawan ${ }^{2}$
}

\begin{abstract}
A capacitor bank is not only used to improve the power factor, but also can be used to reduce losses in the power system network, such as its placement on the primary feeder. The position of the capacitor bank will be affected by the compensation factor and the sharpness of increase loads linearly in a primary feeder. This paper is aimed to determine an optimal location of the capacitor bank in the primary feeder which their loads increasing linearly in order to get maximum loss saving. Mathematical model to determine the optimal location of the capacitor bank has been clearly derived in this paper. Simulation results show that the maximum loss reduction occurs in compensation between $50 \%$ and 100\%, with get loss saving about $52 \%$. In these conditions, optimal locations lay between $75 \%$ and $100 \%$. These results were influenced by the sharpness of the increase loads and the compensation factor. For loads increasing sharply, the position of the capacitor banks will be further away from the substation; whereas for greater compensation factor, the position of the capacitor bank will be getting closer to the substation.
\end{abstract}

Keywords — loss saving, mathematic model, compensation, increasing sharply.

\section{INTRODUCTION}

A $\mathrm{n}$ inductive load in the primary feeder will decrease the power factor of system because generator has to supply reactive power to the load. For feeders with low power factors (less than $89 \%$ ) have to be corrected until the reactive supply become smaller. If the compensation is aimed only for correcting of the power factor of system, the capacitor bank location will be independently (no problem). Another problem appears while correcting the power factor, how much losses in the feeder can be reduced by installing of capacitor bank. It is possible because of the capacitor bank current will reduce reactive current produced by the load (as dominant contribution), so, the current flowing and losses in the feeder can be reduced. Significance of reducing in losses in the feeder is influenced by the location where the capacitor bank is installed [1]. If losses reducing as consider in installation of capacitor bank in the feeder, the capacitor bank location have to be looked for in order to reduce losses to be maximum. Where the losses in the distribution system (primary feeder is dominant) is greater than $60 \%$ from total losses system.

Figure 1 is a primary feeder with lumped load and current (I) flowing in the feeder. Supposed that resistance of the feeder is $\mathrm{R}$, power factor $\left(F_{b} \cos \phi\right)$ lagging and reactance of the feeder is ignored, then, the current flowing in the feeder is also lagging with respect to the voltage by phase angle $\phi$. The current can be formulated as

$$
\begin{aligned}
I & =I \cos \phi-j I \sin \phi \\
& =I_{a}-j I_{r}
\end{aligned}
$$

Where $I_{a}=I \cos \phi$ is an active current and $I_{r}=I \sin \phi$ is a reactive current.

Through Figure 1 that has line resistance, $\mathrm{R}$, losses can be derived from the Equation 1 and yields

${ }^{1}$ Hermagasantos Zein is with Departement of Energy Conversion Technology, Politeknik Negeri Bandung, Bandung, Indonesia. E-mail: hermaga_s@yahoo.co.id.

${ }^{2}$ Erwin Dermawan is with Departement of Electrical Engineering, Universitas Muhammadiyah, Jakarta, Indonesia. E-mail: erwindermawan@yahoo.com.

$$
P_{r}=\left(I_{a}^{2}+I_{r}^{2}\right) R
$$

If at the load is installed the capacitor bank that yield current, $I_{c}$, losses in the feeder can be determined from the Equation 2 and yield

$$
\begin{aligned}
P_{r}^{c} & =\left[I_{a}^{2}+\left(I_{r}-I_{c}\right)^{2}\right] R \\
& =\left[I_{a}^{2}+I_{r}^{2}-2 I_{r} I_{c}+I_{c}^{2}\right] R
\end{aligned}
$$

From the last two equations, the saving power by installing capacitor bank is

$$
\begin{aligned}
\Delta P_{r} & =P_{r}-P_{r}^{c} \\
& =2 I_{r} I_{c}-I_{c}^{2}
\end{aligned}
$$

From Equation 4, the losses which can be saved and depend only on the reactive current. The active current is not shared in this case.

\section{METHOD}

\section{A. Loss Reduction by A Capacitor Bank}

Figure 2 is the reactive current curve in the feeder. This curve is expressed as a function of distance (x) as:

$$
I_{x}=f(x)
$$

Then, the losses can be counted in every segment with distance $d x$ from the feeder in the Figure 2 as:

$$
\partial P_{r r}=3[f(x)]^{2} \frac{R}{L} \partial x^{\prime}
$$

Therefore, total losses along feeder can be counted by integrating the Equation 6 and resulting

$$
P_{r r}=3 \int_{0}^{L}[f(x)]^{2} \frac{R}{L} \partial x
$$

Where $P_{r \mathrm{r}}$ is total losses affected by reactive current, $f(x)$ is reactive current function along feeder, $R$ is total resistance of feeder, $L$ is total distance of feeder and $d x$ is the distance element.

From the Figure 2, let $x$ is the location of a unit capacitor bank from the substation and $I_{c}$ is the phase current of the bank, so the total losses is

$$
\begin{aligned}
P_{r r}^{c}= & \frac{3 R}{L} \int_{0}^{x}\left[f(x)-I_{c}\right]^{2} \partial x=\int_{x}^{L} f^{2}(x) \partial x \\
= & \frac{3 R}{L} \int_{0}^{x}\left[f^{2}(x)-2 I_{c} f(x)+I_{c}^{2}\right] \partial x+ \\
& \frac{3 R}{L} \int_{x}^{L} f^{2}(x) \partial x \\
= & \frac{3 R}{L} \int_{0}^{L} f^{2}(x)+\frac{3 R}{L} I_{c} \int_{0}^{x}\left[I_{c}-2 f(x)\right] \partial x
\end{aligned}
$$


Then loss saving can be determined from the last two equations in unit distance, that is,

$$
\Delta P_{r r}=P_{r r}-P_{r r}^{c}=3 R I_{c} \int_{0}^{x}\left[2 f(x)-I_{c}\right] \partial x
$$

where $d x=d x^{\prime} / \mathrm{L}$. Then the optimal location of the capacitor bank has been able to be determined by deriving the Equation 9 against distance, and the result is

$$
\frac{\partial \Delta P_{r r}}{\partial x}=3 R I_{c}\left[2 f\left(x_{m}\right)-I_{c}\right]=0
$$

The last equation can be simplified further as below.

$$
f\left(x_{m}\right)=\frac{I_{c}}{2}
$$

where $x_{m}$ is optimal location from substation.

\section{B. Feeder with Type of Loads that Increase in Linearly}

Figure 3 is a feeder, 10 nodes, with the type of load that rises linearly along the feeder or the loads are not uniformly distributed. The reactive currents of the loads at each node can be modeled by the Equation 12 .

$$
I_{B}(n)=I+n c I
$$

Where $I_{B}(n)$ is reactive current of the load at node $\mathrm{n}, \mathrm{n}=0$, $1,2, \ldots, \mathrm{N}, I$ is reactive current of the load at the substation and $c$ is constant that states the rising load.

Then from the above equations have been done the calculations for a feeder with $\mathrm{N}=6$ and the results were contained in the Table 1 . This table consists of currents of the loads, feeder currents, changes in the first and second of the feeder currents. The second change of the feeder current is constant, $c I$. Because $c I$ is a constant, then the function of the current flowing in the feeder as a function of changes in $\mathrm{n}$ can be expressed as a second order polynomial or quadratic function. It is formulated in the Equation 13 below.

$$
I_{F}(n)=I_{T}+\left(\frac{c I}{2}-I\right) n-\frac{c I}{2} n^{2}
$$

From the Table 1 can be derived total reactive currents of the all of loads, which states a large of current flows into the feeder from the transformer of substation. The results are written in the following Equation 13.

$$
I_{T}=\left\{(N+1)+\frac{N(N+1)}{2} c\right\} I
$$

If $\mathrm{L}$ is the length of the feeder and $\mathrm{X}$ is the distance from the substation, $\mathrm{X}$ in unit is $\mathrm{X}$.

$$
x(p u)=\frac{X}{L}=\frac{n}{N}
$$

From Equation 12, 14 and 15 can be derived the following equation.

$$
\frac{I_{B}(x)}{I_{T}}=\frac{2+2 N c x}{2(N+1)+(N+1) N c}
$$

Then Equation 16 can be plotted curves of the reactive currents for the constant loads as a function of the variations of c. For $\mathrm{N}=10$ and fixed total reactive current, then the curves of the load reactive currents are shown in Figure 4. The figure shows that the larger the value of $c$, then the load reactive current increases linearly sharper. Whereas for $c=0$, the load current is flat distributed or uniformly distributed.

From the curves can be concluded that the distribution of the load reactive current in the middle of the feeder is not effected by c. This is shown by $x=0.5 \mathrm{pu}$ with same distributed current, 0.09pu. Next, from Equation 13 and 15 can yield a function of distance $x$, that is

$$
f(x)=I_{T}+\left(\frac{c}{2}-1\right) N I x-\frac{N^{2} c}{2} I x^{2}
$$

If $I$ of the Equation 14 is substituted into Equation 17, yielded

$$
\begin{aligned}
f(x)= & I_{T}+\left(\frac{c}{2}-1\right) \frac{2 I_{T}}{2(N+1)+(N+1) N c} N x- \\
& \frac{N^{2} c I_{T}}{2(N+1)+(N+1) N c} x^{2}
\end{aligned}
$$

or,

$$
F(X)=I_{T}\left(1+\beta x-\alpha x^{2}\right)
$$

Where

$$
\begin{aligned}
& \beta=\left(\frac{c}{2}-1\right) \frac{2}{2(N+1)+(N+1) N c} N \\
& \alpha=\frac{N^{2} c}{2(N+1)+(N+1) N c}
\end{aligned}
$$

$\beta$ is always negative for $\mathrm{c}<2$ and $\alpha$ is always positive. The reactive current of the substation, or maximum reactive current, flows into the feeder at $x=0 \mathrm{pu}$, and then it decreases until a minimum value at the end of the feeder at $x=1.0 \mathrm{pu}$, as shown by Figure 5 . For the flat load, the reactive current flowing in the feeder decreased linearly [2]. Whereas for the distribution of the load that increases linearly, the reactive current flowing in the feeder decreased quadratic. Figure 4 shows that the change of the decrease of reactive current flowing in the feeder is very small for increase of the loads of a half times, $c=0.5$, up to three times for $c=3$. This is evidenced by its curves almost coincide.

\section{Optimum Location of A Capacitor Bank}

\section{1) Optimum Location}

Optimum location of a capacitor bank can be determined by substituting Equation 19 into Equation 11 and yield

$$
\frac{k}{2}=1+\beta x_{m}-\alpha x_{m}^{2}
$$

Where,

$$
k=\frac{I_{c}}{I_{T}}
$$

So solution of Equation 22 is

$$
x_{m}=\frac{\beta+\sqrt{\beta^{2}-4 \alpha\left(\frac{k}{2}-1\right)}}{2 \alpha}
$$

For the feeder with $\mathrm{N}=9$, plot $x_{m}$ versus $c$ for variation $\mathrm{k}$ can be shown by Figure 6 . This figure shows that the greater the increase load current, the optimum location is also further away from the substation.

2) Loss Reduction

From Equation 8 and 9, losses which can be saved depend on the location of the capacitor bank along the feeder. Let the location of the capacitor bank is $x$ from the substation, the loss reduction can be determined as below

$$
\begin{aligned}
\Delta P_{r r} & =P_{r r}-P_{r r}^{c}=3 R I_{c} \int_{0}^{x}\left[2 f(x)-I_{c}\right] \partial x \\
& =3 R I_{c} \int_{0}^{x}\left[2 \mathrm{I}_{T}\left\{1+\beta x-\alpha x^{2}\right\}-I_{c}\right] \partial x \\
& =3 R I_{c}\left[\left(2 I_{T}-I_{c}\right) x+\beta I_{T} x^{2}-\frac{2}{3} \alpha I_{T} x^{3}\right] \\
& =3 R I_{T}^{2} k\left[\frac{\left(2 I_{T}-I_{C}\right)}{I_{T}} x+\beta x^{2}-\frac{2}{3} \alpha x^{3}\right]
\end{aligned}
$$

And let the losses of one unit is $3 R I_{T}^{2}$ and the power can be saved (losses saving) in the unit is

$$
\Delta \mathrm{P}_{r r}(p u)=k\left[(2-k) x+\beta x^{2}-\frac{2}{3} \alpha x^{3}\right]
$$

Equation 26 consists of two parameters, $\mathrm{k}$ and $\mathrm{c}$, which affect loss reduction. Parameter $\mathrm{k}$ states amount 
compensation and parameter $\mathrm{c}$ (in parameters $\alpha$ and $\beta$ ) states sharp of increasing distribution loads.

Figure 7 and 8 are simulation of loss reduction with $\mathrm{N}=10$. Figure 7 shows loss reduction for variation $\mathrm{c}$ on fix k. Whereas Figure 8 shows loss reduction for variation $\mathrm{k}$ on fix c. From the two figures state that optimum location of the capacitor bank is extremely affected by the two parameters. The greater the value of the parameters then the optimum location will be close to the substation. Where $m$ is mass of ship and $\delta$ is rudder angle. The indicator of maneuvering performance based on IMO regulation such as Tactical Diameter (TD), advanced $(A d)$ and transfer $(T r)$ were approximated by equation (6) refer to [5].

$$
\begin{aligned}
& \frac{T D}{L}=0.140+1.0 \frac{S T D}{L} \\
& \frac{A d}{L}=1.10+0.514 \frac{T D}{L} \\
& \frac{T r}{L}=0.375+0.531 \frac{T D}{L}
\end{aligned}
$$

\section{RESULT AND DISCUSSION}

From simulation the feeder for $\mathrm{N}=10$ with constant load, the results were shown in the Figure 7 and 8. In this simulation will be studied influences of factor of increase in load current, $\mathrm{c}$, and compensation factor, $\mathrm{k}$.

From Table 2 states that loss reduction is affected by compensation factor, $\mathrm{k}$. Loss reduction will reach maximal for $\mathrm{k}=0.5$ up to 1.0 . For low compensation, $\mathrm{k}<0.5$, will yield small loss reduction, less than $0.13 \mathrm{pu}$. Whereas over compensation is also yield small loss reduction, less than 0.28 . Variations of loss reduction are caused by factor of the increase load current, c, that begin from $c=0$ up to $c=2.5$. The simulation results show rise of loss reduction if $\mathrm{c}$ rise. So from the simulation is get maximum loss reduction, $0.53 \mathrm{pu}$, occur at $\mathrm{c}=2.5$ and $\mathrm{k}=1.0$. For this case, optimum location will more close to substation if factor $\mathrm{k}$ becomes bigger. For maximal loss reduction, optimum location lies at $\mathrm{x}=0.5 \mathrm{pu}$ up to $0.9 \mathrm{pu}$. This is affected by factor $\mathrm{c}$, for big $\mathrm{c}$ then $\mathrm{x}=0.9 \mathrm{pu}$. From the Figure 7, optimal loss reductions occur at compensation factors between 0.5 and 1.0. These conditions yield loss reductions about $50 \%$.

The Figure 8 has shown that loss reduction is small for $\mathrm{k}<0.2 \mathrm{pu}$. These simulation results for $\mathrm{k}$ variations are almost not affect loss reduction and optimum location.
This is shown by the Table 3 . Loss reduction is only small different for change of c. Loss reduction maximum and minimum are about $52 \%$ and $12 \%$, repeatedly; whereas optimum location lies between $55 \%$ and $85 \%$. For small compensation, $\mathrm{k}=0.1$, optimal location is maximum, $\mathrm{x}_{\mathrm{m}}=85 \%$. Otherwise, for over compensation, $\mathrm{k}=1.4$, optimal location is minimum, $\mathrm{x}_{\mathrm{m}}=55 \%$. From the Figure 8, loss reduction optimal occurs at $\mathrm{k}$ between 0.5 and 1.0. On the conditions, optimum locations lay between $70 \%$ and $90 \%$

\section{CONCLUSION}

Capacitor bank position in feeder is truly determining loss saving which depends on the number of nodes or load location and capacity of current compensation produced the capacitor bank.

Mathematic model for determining optimum location of a capacitor bank from main primary feeder that is loaded increasing linearly has been proposed in this paper.

The simulation results in Figure 7 and 8 (or Table 2 and 3) are for the increasing load linearly along main feeder. Optimal loss reduction occurs at the compensation between $50 \%$ and $100 \%$ with optimum location of capacitor bank lays between $75 \%$ and $90 \%$.

\section{REFERENCES}

[1] T. Gonen, "Electrical Power Distribution System Engineering", New York, Mc. Grow Hill, Inc., Copyright, 1986, pp.412-438.

[2] T. Puloka, "Simulation of Resonance in a Small-Scale Network Laboratory,", Proceeding Power on, International Conference on Vol.3., 2000

[3] Zein, H., "Transmission and Distributions", Lecture Dictate, Department of Energy Conversion Technology, Bandung State Polytechnic, 2008

[4] Zein, H., "Optimal Capacitor Bank Location in the Primary Feeder with Typical Flat Load", Conference on Information Technology and Electrical Engineering (CITEE), Department of Electrical Engineering, Faculty of Engineering, Gadjah Mada University, Tuesday, August 4, 2009

[5] Zein, H.," Factor Correction for Energy Losses Through Linear Daily Load Curve Duration Approach", Conference on ICGWBT 2012 Jogya, Ahmad Dahlan University, marc, 20- 2012

[6] Zein, H., "Perkiraan Pasokan Daya Sistem Jawa-Madura_Bali sampai Tahun 2016 Berdasarkan Index LOLP Satu Hari Pertahun", Majalah Ilmiah TRANSMISI, Teknik Elektro Undip, Semarang, 2009.

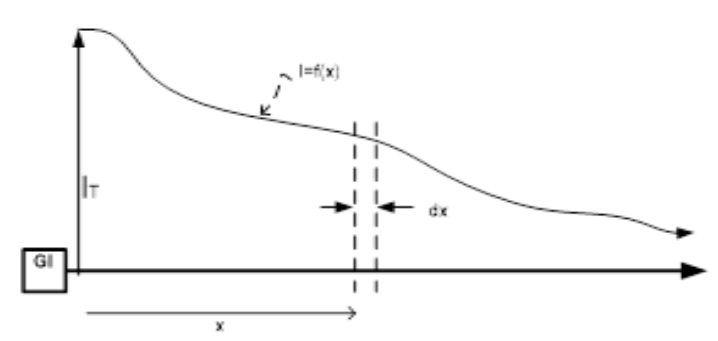

Figure 2. Reactive current versus distance in feeder 


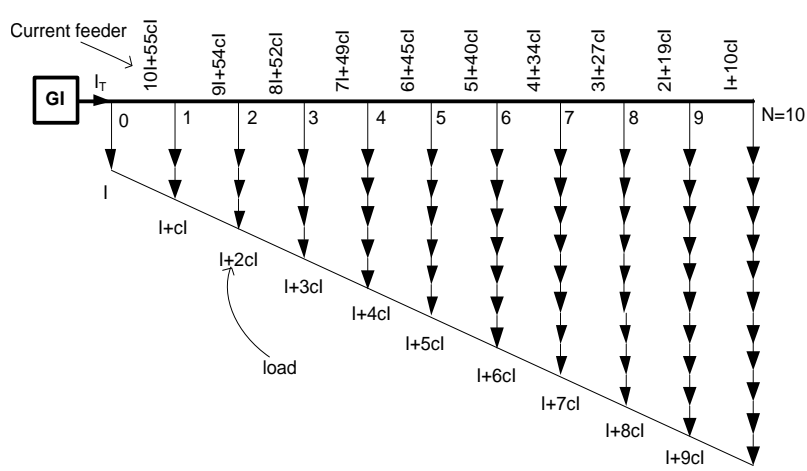

Figure 3. A Feeder with typical linear loads

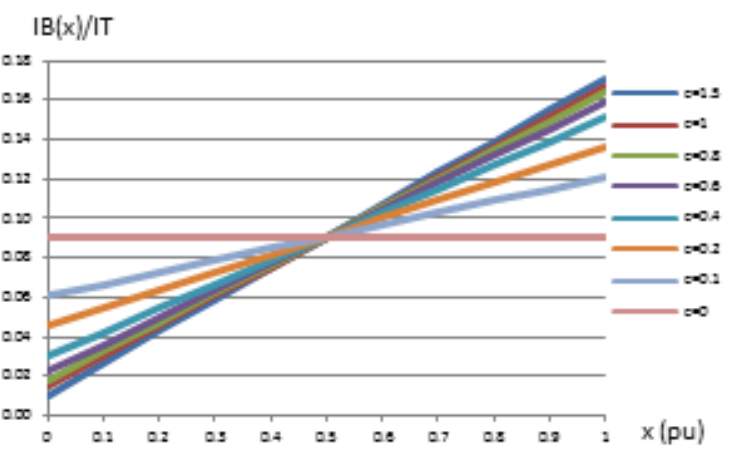

Figure 4. Load reactive current as function of distance for variation $\mathrm{c}$

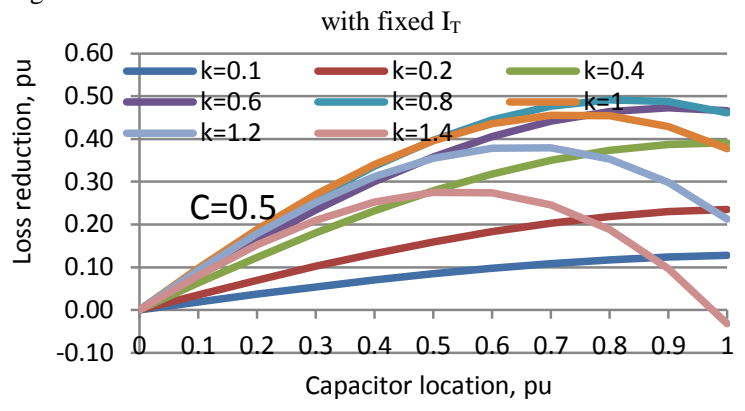

(a)

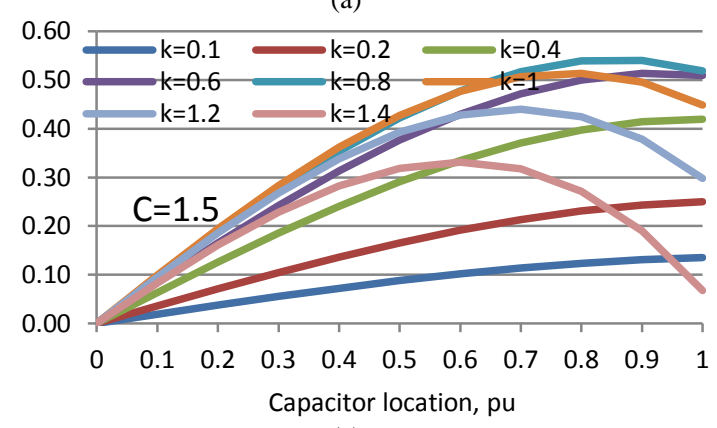

(c)

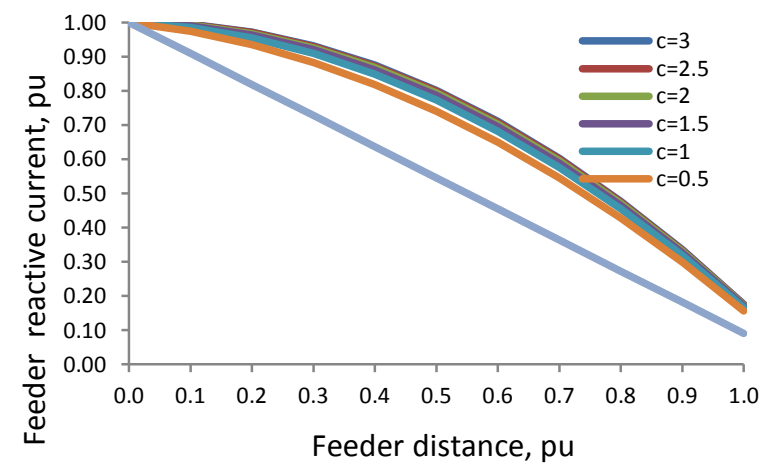

Figure 5. Feeder reactive current as a function of feeder distance for variation $\mathrm{c}$ with fixed $\mathrm{I}_{\mathrm{T}}$

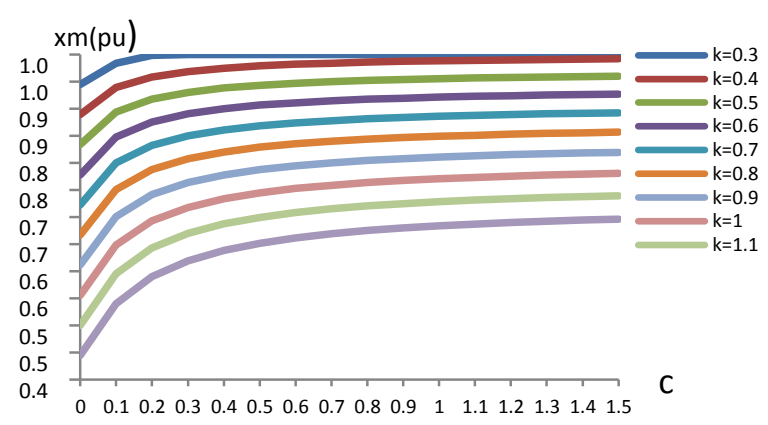

Figure 6. The optimum location vs the increase load current curves for variation $\mathrm{k}$

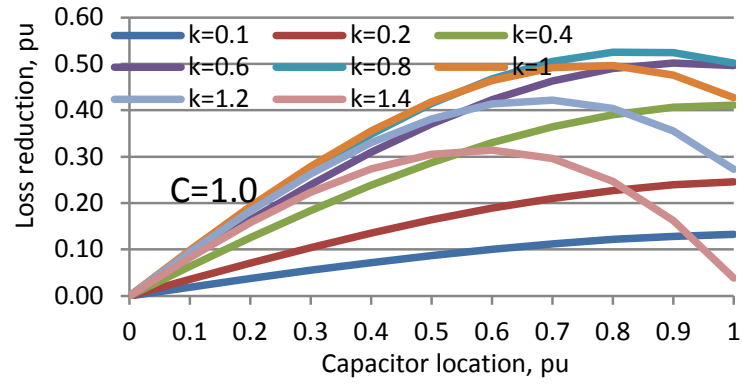

(b)

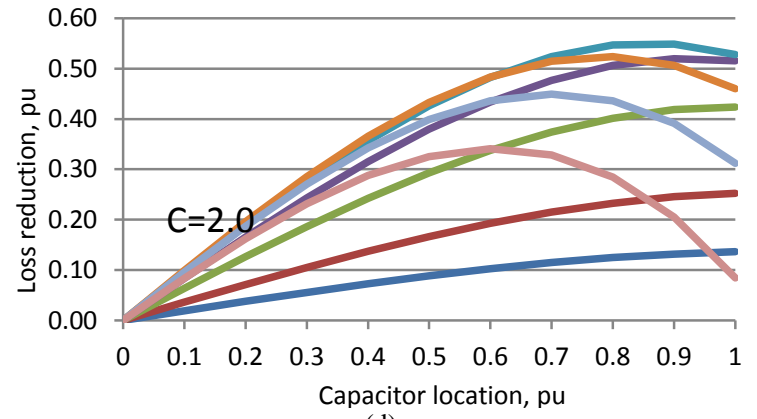

(d)

Figure 7. Loss reduction as a function of the capacitor bank location and linearity distributed loads: (a), (b), (c) and (d) for k=0.1, 0.5, 1.0 and 1.2, reapitively

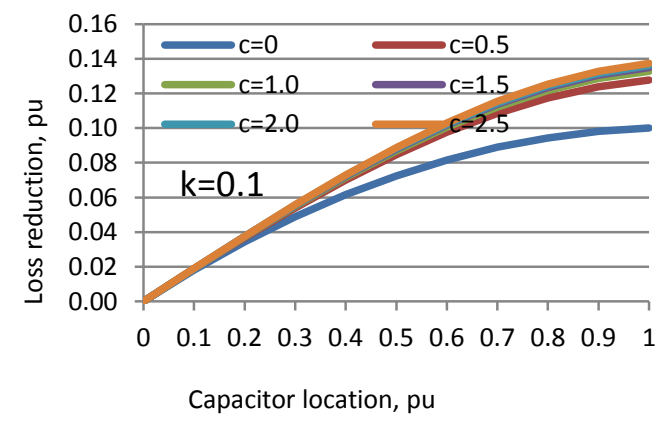

(a)

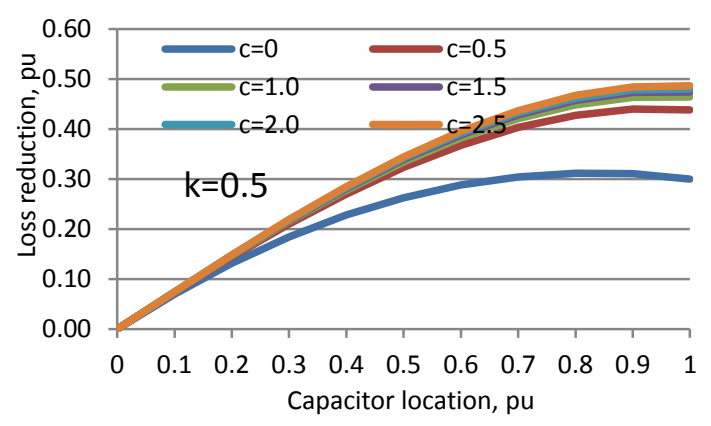

(b) 


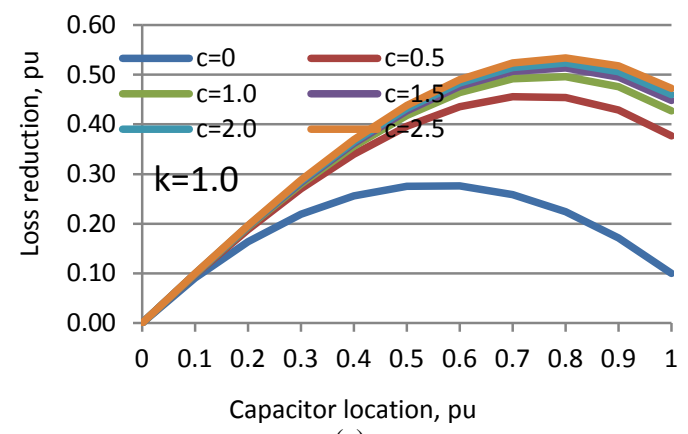

(c)

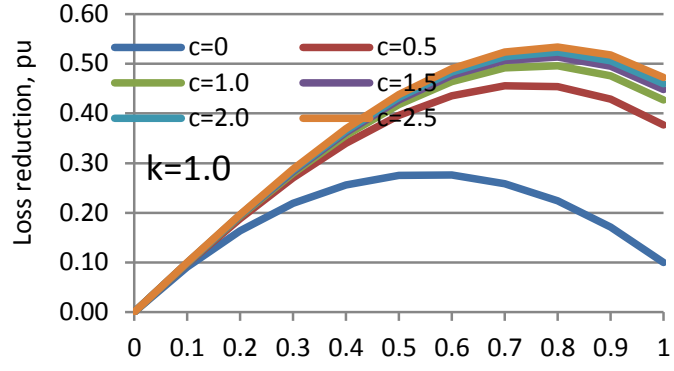

Capacitor location, pu

Figure 8. Loss reduction as a function of the capacitor bank location and linearity distributed loads: (a), (b), (c) and (d) for k=0.1, 0.5, 1.0 and 1.2, reapitively

TABLE 1.

LOAD CURRENTS, FEEDER CURRENTS, CHANGES IN THE FIRST AND SECOND OF THE FEEDER CURRENTS

\begin{tabular}{ccccc}
\hline \hline $\mathrm{n}$ & $\mathrm{I}_{\mathrm{B}}(\mathrm{n})$ & $\mathrm{I}_{\mathrm{F}}(\mathrm{n})$ & $\Delta \mathrm{f}(\mathrm{n})$ & $\Delta^{2} \mathrm{f}(\mathrm{n})$ \\
\hline 0 & $\mathrm{I}$ & $7 \mathrm{I}+21 \mathrm{cI}$ & & \\
1 & $\mathrm{I}+\mathrm{cI}$ & $6 \mathrm{I}+21 \mathrm{cI}$ & $-\mathrm{I}$ & \\
2 & $\mathrm{I}+2 \mathrm{cI}$ & $5 \mathrm{I}+20 \mathrm{cI}$ & $-\mathrm{I}-\mathrm{cI}$ & $-\mathrm{cI}$ \\
3 & $\mathrm{I}+3 \mathrm{cI}$ & $4 \mathrm{I}+18 \mathrm{cI}$ & $-\mathrm{I}-2 \mathrm{cI}$ & $-\mathrm{cI}$ \\
4 & $\mathrm{I}+4 \mathrm{cI}$ & $3 \mathrm{I}+15 \mathrm{cI}$ & $-\mathrm{I}-3 \mathrm{cI}$ & $-\mathrm{cI}$ \\
5 & $\mathrm{I}+5 \mathrm{cI}$ & $2 \mathrm{I}+11 \mathrm{cI}$ & $-\mathrm{I}-4 \mathrm{cI}$ & $-\mathrm{cI}$ \\
6 & $\mathrm{I}+6 \mathrm{cI}$ & $\mathrm{I}+6 \mathrm{cI}$ & $-\mathrm{I}-5 \mathrm{cI}$ & $-\mathrm{cI}$ \\
\hline \hline
\end{tabular}

TABLE 2.

LOSS REDUCTION AND OPTIMUM LOCATION FOR C VARIATIONS

\begin{tabular}{cccc}
\hline \hline $\mathrm{k}$ & $\begin{array}{c}\text { Loss Reduction } \\
(\mathrm{pu})\end{array}$ & $\begin{array}{c}\text { Optimum Location } \\
(\mathrm{pu})\end{array}$ & From \\
\hline 0.1 & $0.10-0.13$ & $0.8-1.0$ & Figure 7a \\
0.5 & $0.31-0.48$ & $0.6-0.9$ & Figure 7b \\
1.0 & $0.28-0.53$ & $0.5-0.8$ & Figure 7c \\
1.5 & $0.10-0.28$ & $0.2-0.6$ & Figure 7d \\
\hline \hline
\end{tabular}

TABLE 3.

LOSS REDUCTION AND OPTIMUM LOCATION FOR K VARIATIONS

\begin{tabular}{cccl}
\hline \hline $\mathrm{c}$ & $\begin{array}{c}\text { Loss reduction } \\
(\mathrm{pu})\end{array}$ & $\begin{array}{c}\text { Optimum location } \\
(\mathrm{pu})\end{array}$ & From \\
\hline 0.1 & $0.10-0.49$ & $0.55-0.85$ & Figure 8a \\
0.5 & $0.12-0.52$ & $0.55-0.85$ & Figure 8b \\
1.5 & $0.13-0.54$ & $0.55-0.85$ & Figure 8c \\
2.0 & $0.14-0.55$ & $0.55-0.85$ & Figure 8d \\
\hline \hline
\end{tabular}

